\title{
A Research of Adaptation for E-Learning System by Learning Preferences
}

\author{
Yogesh Kumar Sharma, Santosh P. Borde
}

\begin{abstract}
-personalized studying takes place while e-getting to know frameworks strive purposeful endeavors to plan instructive encounters that healthy the necessities, targets, abilties, and premiums in their students. The gadget completes customized recommendation of the learning content material in keeping with the scores of these common sequences, provided with the aid of the machine. on this system two modules mastering preferences Acquisition and Interface aspect control. in line with getting to know alternatives, the interface additives are modified The more emphasis is at the kind of records which customers can perceive in higher manner with respect to assessments, exercising, Assignments, and Notes and so forth. $b$. The machine have to be involved approximately the manner of contents and data furnished to the person. The results display suitability of using this recommendation model, so as to indicate online gaining knowledge of sports to inexperienced persons based on their studying style, expertise and preferences.
\end{abstract}

keyword: E-studying, Adaptive E- studying version, learning choices Acquisition and Interface aspect manipulate.

\section{INTRODUCTION}

E-getting to know is the usage of records innovation inside the educating and studying technique. Instructive innovation is the compelling usage of mechanical apparatuses in getting to know. Instructive innovation isn't always confined to excessive innovation despite the fact that, electronic instructive innovation, additionally called e-studying, has changed into a full-size piece of society these days. E-studying includes a wide utilization of digitization methodologies, segments and conveyance techniques. for example, m-studying stresses portability however is commonly indistinct on a essential degree from instructive technology. Instructive innovation consists of various styles of media that convey content, sound, images, motion, and spilling video, and contains innovation programs and techniques, as an instance, sound or video tape, satellite tv for pc tv, CD-ROM, and pc based totally getting to know, just as close by intranet/extranet and online mastering. facts and correspondence frameworks, regardless of whether or not unsupported or dependent on both nearby systems or the net in arranged studying, underlie numerous e-gaining knowledge of forms. fashions of e-learning painting where innovation performs a explicit job in assisting getting to know. these may be portrayed each on the dimension of instructive standards and on the measurement of natty gritty

Revised Version Manuscript Received on 16 September, 2019.

Yogesh Kumar Sharma, Professors, Head of Department, Deparment of Computer science and engineering Research Coordinator Shri JJTU, Rajasthan, India.

(Email: dr.yogeshkumar@yahoo.in)

Santosh P. Borde, 2Research Scholar, 2Deparment of Computer science and engineering, Shri JJTU, Rajasthan, India.

(Email: santoshborde@yahoo.com) exercise in actualizing the ones requirements. in this manner the models can be applied to develop new techniques and to look at advanced gaining knowledge of via this methods. This paper outlines a few powerful and transformative fashions applied for e-gaining knowledge of and improvement of e-gaining knowledge of method.

the main objective of this paper is to observe the concept of adaptive gaining knowledge of, to define its dimensions and to analyze the systems evolved since 2010. To gain this goal, we ought to ask the subsequent questions: what's an adaptive getting to know device? what is the architecture on which any adaptive e-learning machine is primarily based? What are the techniques that we can use to put into effect those models and architectures? And eventually, what are the everyday solutions for every approach?

As of past due noteworthy development has been finished within the formation of e-getting to know frameworks dependent on net-technology. for the duration of this quick period such frameworks have handed the path from fundamental hypertext analyzing material and exams conveyed via WWW to instructive entries incorporating every unmarried instructional asset inside instructive condition. The types of academic substances had been enhanced generously making use of media improvements. The remote agency apparatuses for academic property, instructive associations and their divisions have evolved.

Customarily e-learning frameworks are underlined on the substance age and the greater part of them flop in thinking about the end client, while speaking to it. In this way, shows up the requirement for adjustment to the UI's. Versatile e-learning alludes to an instructive framework that comprehends the learning content and the UI together. End clients have one of kind methods for realizing which may legitimately and in a roundabout way influencing on the learning procedure and its result. So as to execute successful and productive e-learning, the framework ought to be skilled not just in adjusting the substance obviously to the individual attributes of clients yet additionally focus on the versatile UI as per client's prerequisites. Since e-learning is online instructive frameworks which are fit for gathering immense measures of client profile information, information mining and information revelation procedures can be connected to discover fascinating connections between qualities of clients and the arrangement systems embraced by clients to give suggestions through UIs. 
These days, numerous product stages (Learning Space, WebCT and Tool Book) bolster these advancements and make conceivable the fast exchange of instructive substance to e-Learning and offbeat learning with client's decision of this procedure. While some exploration has started to look at the usefulness of e-learning frameworks which had not focused on ease of use issues, specifically to the availability of complex online interfaces. Measures for accomplishing openness by means of specialized details and interface configuration have been set up for the regular Web, be that as it may, it stays to be perceived how far e-learning frameworks are fitting in with these principles, and where the contentions may be between instructive highlights and ease of use.

Normally e-learning of instructive framework gives similar assets to all clients despite the fact that various clients need diverse data as indicated by their degree of information, methods for learning inclinations. Course sequencing is an innovation started in the Area of Intelligent/Adaptive Learning System with the essential intend to give end client/client with the most reasonable grouping of information substance to learn, and succession of learning undertakings (models, work out, issues, substance and so on) to work with. The development of e-learning does not imply that current market items and applications are out of date. Existing e-learning frameworks depend on the amount of data. They neglect to think about a significant factor for the achievement of the framework, to be specific the client.

The versatile UI is fundamental and significant necessity of e-learning frameworks now days, to deal with an individual client. A decent UI encourages successful correspondence between the client and the product. Great plan of such an interface is essential for the achievement of any PC application. Because of this expanding intricacy, makers of Web applications are presented with enormous difficulties to improve the UIs and help clients complete their errands easily. Such rearrangements is testing thinking about the assorted variety of clients as far as age, topography, learning level, etc. An interface that is straightforward for one client probably won't be basic for another. Hence, it is imperative to adjust the UI to various sorts of clients dependent on their profiles.

Versatile UIs likewise make it simpler to consent to the changing principles and guidelines around access control of data. They give greater adaptability to executives in managing such changes. Such versatile interfaces can be utilized in a wide scope of spaces and in an assortment of uses.

The proposed methodology screens the client's activities and attempts to recognize use examples and in like manner modify the interface parts or substance given by the framework. To suit such contrasts in client aptitudes, information and inclinations are imperative to comprehend client's learning style. A versatile UI enables the client to learn various controls by giving direction or specific assistance. A middle of the road option is a blended activity UI, which permits the two sorts of adjustment control: (I) control started by the client (ii) robotized control given by the framework.

\section{LITURATURE SURVEY}

A. Anitha and N. Krishnan (2011): World wide web is an enormous data source, comprehensively utilized for adapting now-a-days because of adaptability of time, sharing of learning assets and foundation and so on., Most of electronic learning framework needs master student association, evaluation of client exercises and students are getting suffocated by tremendous number of website pages in the learning site and they discover challenges in picking appropriate materials applicable to their advantage. This work endeavors to connect with e-students at a beginning period of learning by giving route suggestions. E-learning personalization is finished by mining the web utilization information like ongoing perusing chronicles of students of comparable premium. The proposed technique utilizes upper estimate based harsh set grouping and dynamic all kth request affiliation principle digging utilizing apriority for customizing e-students by giving learning easy routes. The substance of brushing affiliation principle and bunching is that, utilizing grouped access examples can lessen the informational index size for affiliation guideline mining task, and improves the proposal precision.

Ahmad Baylari, and Gh. A. Montazer (2007): In online instructive frameworks the structure of learning area and substance are normally exhibited in the static way, without considering the students' objectives, their encounters, their current information, their capacity (known as lacking adaptability), and without intelligence (implies there is less open door for accepting moment reactions or criticisms from the educator when students need support). Accordingly, considering personalization and intelligence will build the nature of learning. In the opposite side, among various segments of e-learning, evaluation is a significant part. By and large, the procedure of guidance finishes with the appraisal and it is utilized to assess students' learning productivity, ability and information. Be that as it may, in online instructive frameworks there is less consideration on versatile and customized evaluation. Having thought about the significance of tests, this paper proposes a customized multi-operator e-learning framework dependent on thing reaction hypothesis (IRT) and counterfeit neural system (ANN) which presents versatile tests (in view of IRT) and customized suggestions (in view of ANN). These specialists add adaptively and intuitiveness to the learning condition and go about as a human teacher which aids the students in a neighborly and customized educating condition.

A. Al-Azawei and A. Badii (2014): This paper researches the instructive premise of Adaptive Educational Hypermedia Systems (AEHS) that consolidate Learning Styles so as to suit client's learning style inclinations and necessities. In this way, AES adjust the learning content, its introduction and route to the client's learning style inclinations. We gather thirty three Adaptive and Intelligent Web-based Educational Systems (AIWBES) that fuse learning styles and examine twenty of them, to be specific the AEHS, as the remaining are Intelligent Tutoring Systems. The fundamental accomplishment of this work is the examination of AEHS' 
academic premise as far as adjustment rules. We infer that these frameworks pursue comparable examples in their adjustment rationale.

Ali Tarhini et. Al (2014): the guideline objective of our evaluation is to (1) exactly check out the additives that impact the confirmation and use of e-learning in Lebanon, and (2) inspect the interest of a ton of man or woman versions as mediators (e.G., age, sex, contribution, enlightening stage) in a broadly inclusive technology reputation model (TAM). A quantitative method method became grasped on this exam. to check the speculated research version, information come to be assembled from 569 college students and postgraduate understudies packing in Lebanon with the aid of techniques for survey. The assembled records had been inspected the usage of Structural Equation Modeling (SEM) framework trouble to AMOS structures diagnosed with multi-bundle examination. The stop end result discovered out that apparent supportiveness (PU), saw comfort (PEOU), conceptual gauges (SN) and pleasant of labor life (QWL) strongly effect understudies' direct preference (BI). We furthermore placed that enjoy coordinates the association among PEOU, PU and $\mathrm{SN}$ on e-gaining knowledge of use goal, and that age differentiation coordinates the outcomes of PEOU, SN and QWL on BI. also, informational degree preservationists the consequences of PEOU, SN on BI, and sex direct the outcomes of PU, SN and QWL on BI. notwithstanding wants, a coordinating activity of age at the association among PU and BI modified into not located. in the end, sex changed into not observed to effect the association amongst PEOU and BI, and enlightening degree failed to on the spot the affiliation amongst PU or QWL and BI. In mild of those revelations, suggestions to each principle and exercise are mentioned.

Behram Beldagli and Tufan Adiguzel (2010): advancement in net and sight and sound advances has vehemently stimulated the possible utilization of e-reading conditions. while putting off the presence controls made a beneficial gaining knowledge of condition for e-customers, having a numerous accumulating of onlookers (one-of-a-kind locations, records stages, establishments or getting to know limits) obliged the planners of e-learning systems to make flexible and versatile e-gaining knowledge of activities with the ability of enhancing the understudy execution. no matter the way that e-gaining knowledge of structures with adaptively limits had been made to address the ones flexibility issues with the aid of the use of converting the acquaintance of substances with healthy every person patron, they don't satisfy all adaptable associated wishes on a essential stage and alertness. Thusly, extra research and framework are should had been organized to use e-getting to know conditions beneficially as an alternative as opposed to traditional ones. This evaluation speaks to potential additives of an tremendous bendy e-gaining knowledge of with their definitions and practices.

C. Romero and S. Ventura (2006): currently there may be an extending electricity for data mining and enlightening structures, making academic statistics mining as a few other growing research prepare. This paper contemplates the usage of information mining to conventional informational systems, explicit digital guides, definitely comprehended mastering content material corporation structures, and bendy and savvy on-line enlightening systems. All of those systems has unique records source and desires for buying the keep of locating. ensuing to preprocessing the available facts for each circumstance, statistics mining frameworks may be related: studies and portrayal; grouping, portrayal and unique case acknowledgment; connection popular mining and version mining; and substance mining. The accomplishment of the large work desires substantially more and more express work all together for enlightening information mining to convert into a create vicinity.

Chun-Hui Wu et al (2017): Adaptive getting to know for man or woman understudies has starting late ended up being top notch in steerage. This exam plans to fill the void inside the gift composition with the resource of form a flexible e-studying device with self-assessment rubrics reliant on the dynamic stage speculation because of unique understudy desires. inside the interim, the explanation inside the lower back of this exam is to research the ampleness of the use of adaptable e-learning with dynamic systems and rubrics in empowering understudies' mastering outcomes. A check arrangement grow to be coordinated to survey studying sufficiency and learning satisfaction in the Excel (spreadsheet) of the path for the use of the made adaptable e-getting to know system. Sixty faculty understudies from an development college in primary Taiwan appeared into this test have a take a look at and carried out a pretest and a posttest. studies consequences discovered that the made flexible e-mastering shape can fairly improve understudies with altered learning substances and appropriately allows understudies secured statistics and make scholarly limits. The results suggest that educators need to use rubrics as a self-evaluation mechanical meeting for supporting understudies with dynamic ranges to coordinate an understudy focused e-reading circumstance. similarly, the nonattendance of generalizability is certainly a repression of the winning statistics as a result of a few human beings. sooner or later, destiny research heading of this evaluation have become moreover noted.

D. Arotaritei and S. Mitra (2004): this newsletter gives an audit of the available composition on comfortable internet mining. the one of a kind pieces of web mining, as an example, amassing, connection rule mining, route, personalization, Semantic net, statistics recovery, substance and photo mining are considered below the modern-day-day logical type. The interest off cushioned units in handling the exclusive types of vulnerabilities/vulnerability is covered. A hybridization off feathery gadgets with innate computations (some different fragile enrolling machine) is delineated for information restoration. An expansive rundown of sources is moreover included.

D. Pierrakos et. Al (2003): This paper is an audit of progressing paintings inside the location of net use burrowing to help check out on the personalization of net-based totally facts groups. The substance of personalization is the adaptability of statistics structures to the requirements of their customers. This problem is polishing off logically essential on the web, as non-ace clients are beaten by the diploma of data available on the net, while commercial agency internet areas try to assemble the estimation of their companies in order to make enduring dating with 
their visitors clients. this text factors of view net personalization thru the gem of personalization methodologies grasped via web areas and understanding a mixture of limits. on this specific situation, the region of net use mining is a powerful wellspring of contemplations and methodologies for the execution of personalization convenience. We along those lines gift an investigation of the most current art work in the area of internet use mining, focusing on the troubles which have been perceived and the plans which have been proposed.

F. Doelitzscher et. al. (2014): It has been built up through writing that, if an e-learning framework could adjust to learning attributes of students, it will expand learning execution and substance information obtaining of students. that set out an establishment for application and execution. We evaluated drifts in versatile e-learning framework improvement, make an informative on learning-style models towards students' learning character and propose an Architectural model of Automatic Adaptive E-learning System (AAeLS) in view of learning-style idea/models. The idea it to display an e-learning framework that will consequently adjust to learning inclination of clients', the framework find out about clients' learning style while the client get familiar with the material substance of the framework; hence the learning procedure in two different ways, the framework is realizing when the client is learning. We prescribe further work on execution and testing of the model, in a connected research.

\subsection{Need of work:}

1. Design an E-learning application to provide online courses for the specific domain subjects.

2. Capture the learning behavior of an Individual User using Web Usage Mining.

3. Analyze the captured learning patterns and identify the learning preferences of the user in their respective web sessions.

4. Design and validate the adaptation mechanism according to user's preferences for the specific course.

5. Recommend the adaptation based using rule-based classification

\section{METHODOLOGY \& RESULTS}

The fundamental goal of research is on Adaptive User Interface which incorporates versatile introduction and versatile route for e-learning condition. To accomplish the referenced target the examination is four crease: 1) Identify learning inclinations utilizing Web Usage Mining to recognize diverse utilization examples of clients [3][4]. 2) Depending on the learning inclinations, execute the suggestion framework with versatile UI.

\section{Two Major Modules of Research:}

\section{Learning Preferences Acquisition:}

To display a way to deal with perceive the learning inclinations of individual client as per the activities or routes that the person in question has performed on an e-learning application utilizing Web Usage Mining (WUM). Web log mining is significantly the significant piece of Web Usage This paper is a fundamental research work for information

Mining calculation which includes change and elucidation of the logging data to distinguish the learning inclinations of clients [11][17]. Eventually these examples are valuable to order different characterized profiles relies upon substance types and to give customized learning condition to the client regarding Adaptive User Interface.

\section{Interface Component Manager:}

After identifying the categories of users the Interface component manager is changing the graphical representation of user interface based on small applications of E-learning portal.

\section{Benchmark data for validation of the model:}

E-learning substance is the archive of putting away and organizing the instructional substance in the specific space for example course. The substance obviously ought to adaptively produce for the Interface segment chief. For various clients, the framework should display the suitable data that clients can comprehend as versatile interface. To approve the framework "C Programming Language" Course will think about the benchmark information. For the referenced course various kinds of substance like content, graphical, video, showing, activities and evaluations tests will produce.

\section{CONCLUSION}

The essentialness of proposed shape is to increase ordinary e-analyzing machine by using the ease of giving adaptability in UI the usage of learning tendencies. all the even as, such an adaptable LMS need to no longer to lose its ease and must maintain being clear and easy to use for educators. to provide flexibility in LMS, the studying inclinations of clients need to be acknowledged first. Thusly, a modified customer showing come nearer from the direct and physical video games of customers need to be made. The proposed perception offers distinguishing their purchaser's learning dispositions in a easy way. The recognized facts may be used to make customers and instructors to cautious the client's getting to know inclinations, helping clients to all the greater right away apprehend their reading technique and prodding educators to widen their training strategies or substances within the occasion that they do not make more potent unique mastering tendencies. As in line with gaining knowledge of tendencies, the interface components are changed: a. The more accentuation is at the form of records which customers can see in higher way regarding checks, exercising, Assignments, and Notes and so on.

B.The framework ought to be worried about the method for substance and records gave to the purchaser.

C. Chat software program, e mail, discussion forum are the robust capacities for this form of category.

D.This sort of magnificence is quite looking ahead to the right statistics access, and moreover need to attention on execution factors of the customers. 


\section{REFERENCES}

1 A. Anitha, Dr. N. Krishan, "A Dynamic web Mining Framework for E-mastering suggestions making use of tough units and affiliation Rule Mining", international journal of laptop programs Vol. 12, No.11, pp. 36-forty one, (2011)

2 Ahmad Baylari, Gh.A. Montazer, "structure a customized e-studying framework depending on problem reaction hypothesis and counterfeit neural device approach", Elsevier magazine on expert systems with packages, $\mathrm{pp}$. 8013-8021, (2009)

3 A. Al-Azawei and A. Badii, "slicing fringe of mastering styles-based completely versatile instructive hypermedia frameworks (ls-baehss)," global magazine of computer technological know-how and statistics generation, vol. 6 , no. three, p. 1, 2014.

4 A. Tarhini, okay. Sharpen, and X. Liu, "The impacts of character contrasts on e-studying customers conduct in growing international locations: A basic condition version," computers in Human conduct, vol. forty one, pp. 153-163, 2014

5 B. Beldagli and T. Adiguzel, "Outlining a sincerely ideal bendy e-getting to know: An applied device," Procedia Social and Behavioral Sciences, vol. 2, no. 2, pp. 5755-5761, 2010.

6 C. Romero, S. Ventura, "Instructive facts mining: a top level view from 1995 to 2005", published in expert systems with programs pp. one hundred thirty 5-146 Elsevier (2007).

7 C. H. Wu, Y. S. Chen, and T. C. Chen, "A flexible e-analyzing framework for reinforcing analyzing execution: based totally on effective platform speculation," Eurasia journal of arithmetic, science and generation training, vol. 14, no. three, pp. 903-913, 2017

8 D. Arotaritei and S. Mitra, "web mining: a have a look at within the fluffy shape," Fuzzy sets and systems, vol. 148, no. 1, pp. 5-19, 2004.

9 D. Pierrakos, G. Paliouras, C. Papatheodorou, and C. D. Spyropoulos, "internet usage digging as an tool for personalization: A examine," consumer Modeling and person-tailored interaction, vol. thirteen, no. 4, pp. 311-372, 2003.

10 E. Popescu, C. Badica, and L. Moraret, "alluring studying styles in a flexible instructive framework," Informatica, vol. 34 , no. 4, pp. 451-462, 2010

11 F. Doelitzscher, A. Sulistio, C. Reich, H. Kujis, and D. Wolf, "A proposed engineering model for a programmed flexible e-analyzing framework relying on customers gaining knowledge of style," international journal of superior pc technological know-how and packages, vol. five, no. 4, pp. 1-five, 2014.

12 G. Sudhamathy, Dr. C. Venkateshwaran, "internet Log Clustering processes-A Survey", worldwide journal on pc technological know-how and Engineering, pp. 2896-2903, (2011).

13 H. M. Truong, "Coordinating studying patterns and flexible e-reading framework: modern enhancements, troubles and openings," computers in Human conduct, vol. Fifty five, pp. 1185-1193, 2016.

14 H. Park and H.- D. Melody, "Make e-reading smooth! impact of an updated UI on convenience thru using an affordance configuration approach," global magazine of data and training technology, vol. 18, no. 3, pp. 185-196, 2015

15 H. Liu and V. Ke`selj, "Consolidated mining of web server logs and internet substance for grouping customer route designs and looking ahead to clients' destiny solicitations," records and know-how Engineering, vol. 61, no. 2, pp. 304-330, 2007.

16 J. Feldman, A. Monteserin, and A. Amandi, "Programmed identification of mastering patterns: exceptional in beauty," artificial Intelligence evaluate, vol. forty four, no. 2, pp. 157-186, 2015.

17 Jyoti, Dr. A. ok. Sharma, Dr. Amit Goel, "a singular technique for Clustering net patron durations making use of RST", international journal on pc technology and Engineering, pp. fifty six-61, (2009)

18 ok. Suresh, R. Madana Mohna, A. Rama Mohan Reddy, "improved FCM set of rules for Clustering on net utilization Mining", international journal of pc technological know-how issues, pp. 42-forty five, (2011)

19 M. A. Hogo, "evaluation of e-students behavior making use of precise fluffy bunching models: a relative report," international magazine of laptop science and information era, vol. 7, no. 2, pp. 131-one hundred forty, 2010.

20 M. Abdullah, W. H. Daffa, R. M. Bashmail, M. Alzahrani, and M. Sadik, "The effect of studying patterns on pupil's exhibition in e-gaining knowledge of circumstance," worldwide magazine of advanced computer technological know-how and programs, vol. 6, no. nine, pp. 24-31, 2015.

21 M. Jafari, F. SoleymaniSabzchi, and S. Jamali, "isolating clients navigational behavior from net log data: a pinnacle level view," journal of laptop Sciences and programs, vol. 1, no. 3, pp. 39-45, 2013.

22 N. Lakshmi, R. S. Rao, and S. S. Reddy, "A diagram of preprocessing on net $\log$ information for web use research," global magazine of modern era and Exploring Engineering (IJITEE), vol. nine, no. 1, pp. 274-279 2013.

23 Olfa Nasraoui, Maha Soliman, Esin Saka, Antonio Badia, Richard Germain, "a web utilization Mining Framework for Mining Evolving user Profiles in Dynamic internet web sites", IEEE Transaction on expertise and facts Engineering vol. 20, No. 2, (2009).

24 O. Tak'acs, J. 'Sarmanov'a, and ok. Kostol'anyov'a, "research of analyzing styles for flexible e-mastering," in virtual statistics Processing and Communications. Springer, 2011, pp. 368-376.

25 P. Shi, "A gifted method for grouping net get right of entry to designs from internet logs," international magazine of advanced science and generation, vol. 5, no. 1, pp. 354-362, 2009.

26 Renata Ivancsy and Ferenc Kovac, "Grouping techniques applied in net utilization Mining", fifth WSEAS global convention on artificial Intelligence, information Engineering and Database, pp. 237-242, (2006)

27 R. Mahajan, J. Sodhi, and V. Mahajan, "Use designs disclosure from a web join up an Indian e-learning net website online: A contextual studies," education and statistics technologies, vol. 21, no. 1, pp. 123-148, 2016.

28 Sophia Petridou, Vassiliki Koutsonikola Athena Vakali, Georgious Papadimitriou, "Time conscious internet customers Clustering", IEEE Transaction on understanding and information Engineering, pp. 1-15, (2007)

29 S. Ouf, M. A. Ellatif, S. E. Salama, and Y. Helmy, "A proposed worldview for notable learning situation depending on semantic net," computers in Human behavior, vol. Seventy two, pp. 796-818, 2017.

30 U. Markowska-Kaczmar, H. Kwasnicka, and M. Paradowski, "Savvy methods in personalization of learning in e-studying frameworks," Computational Intelligence for technology more desirable studying, pp. $1-23,2010$.

31 Convolutional Neural community", international magazine of computer Sciences and Engineering, Vol.- 6, issue-6, June 2018. E-ISSN: 2347-2693.

Published By:

Blue Eyes Intelligence Engineering 
32 V. S. Dhaka, Manoj Kumar, Harshit Sharma," individual popularity of Offline Handwritten English Scripts: A evaluation", special convention issue: countrywide convention on Cloud Computing and huge statistics, 2010 ..

33 Framework for privacy keeping category in data Mining ,DYK Sharma, GM Sharif, magazine of rising technology and innovative research five (nine), 178-183

34 overall performance evaluation of delay Tolerant Networks Routing Protocols under various Time of live, VK Samyal, DYK Sharma global magazine of boost research in pc technological know-how (IJARCS) eight

$35 \mathrm{Li}-\mathrm{Fi}$ the most current Innovation in wireless verbal exchange S Saini, DYK Sharma worldwide journal of advanced studies in computer science and software program.

36 web page classification on news Feeds the use of Hybrid method for Extraction ad Patel, DYK Sharma facts and conversation era for savvy framework 107 (6), 399-405.

37 impact of cushion length on diverse drop strategies (DLR, MOFO and E-Drop) for MaxProp Routing Protocol in DTN VK Samyal, DYK Sharma worldwide magazine of research in implemented technological know-how and Engineering

38 a pragmatic assessment of pressure and performance trying out technology for net based packages $\mathrm{P}$ sonkari, DYK Sharma IEEE, Amity global conference on artificial Intelligence (AICAI), 399-403

39 impact of network Load and hub Mobility on the exhibition of Proactive, Reactive and Hybrid directing conventions of MANET V Singla, YK Sharma global magazine of superior research in pc technological know-how eight (3

40 evaluation of egocentric Node conduct in put off Tolerant Networks Routing Protocols VK Samyal, DYK Sharma worldwide magazine of modern studies in technological know-how and Engineering

41 importance have a look at OF person internet get entry to statistics MINING FOR business INTELLIGENCE, ad Vyas, YK Sharma Indian magazine of carried out studiesA COMPREHENSIVE STUDY ON CLASSIFICATION OF AUTOMATED CATEGORIZATION OF WEB SITES: A PROPOSED METHODOLOGY DA Vyas, DYK Sharma INDIAN JOURNAL OF APPLIED RESEARCH (IJAR)

42 Using Open CV for Machine Learning in Real Time Computer Vision and Image ProcessingP S, YK SharmaInternational Journal of Recent Technology and Engineering 